\title{
Comparison of cortisol and inflammatory response between aged and middle-aged patients undergoing total hip arthroplasty: a prospective observational study
}

\author{
Jian Zhong, Hai-bo Si, Yi Zeng, Jing Yang, Zong-ke Zhou, Peng-de Kang, Fu-xing Pei and Bin Shen *io
}

\begin{abstract}
Background: To investigate the differences in the perioperative serum cortisol, C-reactive protein (CRP) and interleukin-6 (IL-6) levels between aged and middle-aged patients undergoing total hip arthroplasty (THA).

Methods: Sixty patients (30 aged and 30 middle-aged) undergoing THA for osteoarthritis between August 2016 and January 2017 participated in this study. Blood samples were collected preoperatively and at 6 hours, 24 hours and 3 days after surgery to measure the cortisol, CRP and IL-6 concentrations. The clinical outcomes were assessed using the visual analogue scale (VAS) pain score and Harris hip score (HHS).

Results: No significant differences were found between the two groups before the operation in the cortisol, IL-6 and CRP levels; the VAS score; or the HHS. Cortisol was significantly lower at 6 hours after surgery in the aged group than in the middle-aged group $(P<0.05)$. IL- 6 at 6 and 24 hours after surgery, CRP at 3 days after surgery and the VAS score at 6 and 24 hours after surgery in the aged group were significantly higher than those in the middle-aged group $(P<0.05)$. In the aged group, weak correlations were found between the cortisol concentration 6 hours after THA and the IL- 6 level 24 hours after THA $(r=-0.37, P=0.04)$ and between the IL-6 level 6 hours after THA and the VAS score 24 hours after THA $(r=0.42, P=0.02)$.

Conclusion: Aged patients showed lower cortisol levels at 6 hours after surgery and higher IL-6 levels at 6 and 24 hours after surgery than middle-aged patients undergoing THA.
\end{abstract}

Keywords: Arthroplasty, Hip, Cortisol, Aged, Middle aged

\section{Background}

Life expectancy has been prolonged considerably due to improved healthcare. The prevalence of osteoarthritis $(\mathrm{OA})$ is almost $70 \%$ in women and $60 \%$ in men over the age of 65 years, and most people who suffer from OA display radiographic evidence and/or clinical symptoms $[1,2]$. Total hip arthroplasty (THA) is an effective method to ease pain and improve the quality of life for people who suffer from serious pain and disability caused by OA [3-6].

However, surgeries can trigger stress responses, including a series of immunological, metabolic and hormonal

\footnotetext{
* Correspondence: shenbin_1971@163.com

Department of orthopaedics, West China Hospital, Sichuan University, Chengdu 610041, People's Republic of China
}

changes [7-10]. As one crucial constituent of the stress response, cortisol secretion is inevitably increased after surgery $[11,12]$. Human ageing causes homeostasis disturbances in all systems, with a progressive loss of structural and physiological integrity and function [13]. In particular, impairment of the suprachiasmatic nucleus, which affects the limbic region, hippocampus and hypothalamus, leads to adrenocortical secretion management disorders in aged people $[14,15]$.

Although several studies have compared cortisol levels between aged and middle-aged patients undergoing other operations, the conclusions have been inconsistent [16-19]. To the best of our knowledge, no study in the major English language medical databases has reported the cortisol levels of aged and middle-aged patients 
undergoing THA. We performed this study to investigate differences in cortisol levels between aged and middle-aged patients undergoing THA and the relationship between endogenous cortisol and the inflammatory response after the operation. We hypothesized that aged patients undergoing THA would show a higher level of cortisol and lower interleukin-6 (IL-6) and C-reactive protein (CRP) levels postoperatively than middle-aged patients due to the anti-inflammatory effect of endogenous cortisol production.

\section{Method}

\section{Patients}

Patients aged over 40 years and scheduled for primary unilateral uncemented THA for OA between August 2016 and January 2017 were screened in this prospective, non-randomized, observational study. The exclusion criteria were as follows: senile dementia, steroid use within the past 6 months, chronic malnutrition, smoking, alcoholism, drug abuse, rheumatoid arthritis, hypertension, diabetes mellitus and other systemic diseases that would influence the neuroendocrine and inflammatory responses. The administration of non-steroidal antiinflammatory drugs (NSAIDs) was suspended four weeks before the operation. Of the 68 eligible patients, 7 patients refused to participate, and 1 patient withdrew from this study. Finally, 60 patients were included in the study. The patients were divided into an aged group (over 65 years) and a middle-aged group (40-65 years). This study was conducted in accordance with the Declaration of Helsinki and approved by the local Ethics Committee. All patients gave informed consent prior to their inclusion in the study.

\section{Surgical procedure}

All surgeries were performed by one single experienced surgeon (B.S.). Generally, $1.5 \mathrm{~g}$ of cefuroxime was given within $30 \mathrm{~min}$ before the beginning of surgery, and general anaesthesia was used in all cases. The same operative technique was used. Through the posterolateral approach, the acetabular component was placed at $20^{\circ}$ anteversion and $45^{\circ}$ abduction, the femoral component was fixed at $15^{\circ}$ anteversion, the capsular flap and the short external rotators were repaired in all cases, and wound drainage was indwelled in every patient.

\section{Perioperative management}

Preadmission counselling was given by qualified nurses, and the preliminary assessment was conducted by a doctor. Clear oral fluids were administered up to $3 \mathrm{~h}$ before the operation to minimize preoperative fasting. No sedative was used before surgery. One hundred milligrams of ropivacaine (100 mg: $10 \mathrm{ml}$ ) was diluted with $30 \mathrm{ml}$ of saline and subcutaneously injected around the wound as a local infiltration analgesia.

Forty milligrams of parecoxib was given by intramuscular injection at $6 \mathrm{~h}$ after surgery. A second dose of $40 \mathrm{mg}$ of parecoxib was given at 8:00 a.m. on postoperative day (POD) 1, followed by oral celecoxib (200 mg) every $12 \mathrm{~h}$. Ten milligrams of rivaroxaban was given orally $8 \mathrm{~h}$ after the operation and then administered at 24-h intervals on the subsequent days provided that no bleeding events occurred.

At 8:00 a.m. on POD 1, wound drainage and the monitor were removed, and unrestricted food intake was permitted. Daily functional training, including walking and muscle power exercises, was guided and supervised by a physiotherapist.

\section{Outcome assessments}

Venous blood samples were collected in the morning of the day before surgery from each patient as baseline. The primary outcome was the serum cortisol level. Blood samples to measure the cortisol, CRP and IL-6 levels were obtained at $6 \mathrm{~h}, 24 \mathrm{~h}$ and 3 days postoperatively. After removing cells and debris by centrifugation, the samples were stored at $-80{ }^{\circ} \mathrm{C}$ prior to the analysis. All measurements were performed at the clinical key laboratory of West China Hospital, which was certificated by the College of American Pathologists (CAP). CRP was measured using the rate nephelometric assay on the IMMAGE ${ }^{\circ} 800$ Access immunoassay system (Beckman Coulter Inc., Brea, CA, USA) and reported in milligrams per litre $(\mathrm{mg} / \mathrm{L})$. IL-6 and cortisol were measured with electrochemiluminescence immunoassays (ECLIs) on the modular analytics E170 module (Roche Diagnostics, Mannheim, Germany) and were presented in picograms per millilitre $(\mathrm{pg} / \mathrm{mL})$ and nanomole per litre $(\mathrm{nmol} / \mathrm{L})$, respectively.

Visual analogue scale (VAS) pain scores (rest pain) were marked on the day of hospitalization and $6 \mathrm{~h}, 24 \mathrm{~h}$, 2 days, and 3 days after surgery by a mediatinus (no pain $=0$, worst pain $=10$ ). The Harris hip scores $(H H S)$ were obtained at the time of hospital admission and 3 months postoperatively to evaluate the early recovery effect. Adverse events were recorded at each follow-up.

\section{Statistical analysis}

Data were collected using Excel. Continuous variables are presented as the means and standard deviations $(M \pm S D)$. Dichotomous data are presented as numbers for each category. To compare data between two groups, the normality of all quantitative data was tested with the Shapiro-Wilk test. For normally distributed data, Levene's test for equality of variances was used to test the homogeneity of variances of matching data from two groups, and the two independent samples $t$-test was adopted if the 
variances were homogenous; otherwise, a $t$-test was performed. For non-normally distributed and ranked data, a nonparametric test (Mann-Whitney rank-sum test) was conducted. For enumeration data, the Chi-square test was employed. Because some of our variables (cortisol before and $24 \mathrm{~h}$ after surgery in the middle-aged group, IL-6 at 6, $24 \mathrm{~h}$ and 3 days after surgery in the middle-aged group, and CRP before and at $6 \mathrm{~h}$ after surgery in both groups) were not normally distributed, analysis of variance (ANOVA) of repeated measurement data was not used. Pearson's correlation coefficient and Spearman's rank correlation coefficient were calculated for variables with normal and non-normal distributions, respectively, within each group to analyse their possible correlations. The analyses were performed using the SPSS statistical software (Version 13.0, SPSS Inc., Chicago, IL, USA).
For all comparisons, a $P$ value $<0.05$ was considered significant.

\section{Results}

The patient screening and processing steps are illustrated in Fig. 1.

\section{Patient demographics and operative information}

The two groups were well matched for gender, height, weight, BMI, and operating time (Table 1).

\section{Serial changes of cortisol}

The mean preoperative cortisol levels did not significantly differ between the two groups. Six hours after surgery, serum cortisol increased from 314.84 \pm 89.65 $\mathrm{nmol} / \mathrm{L}$ and $291.93 \pm 111 \mathrm{nmol} / \mathrm{L}$ at baseline to $701.85 \pm$

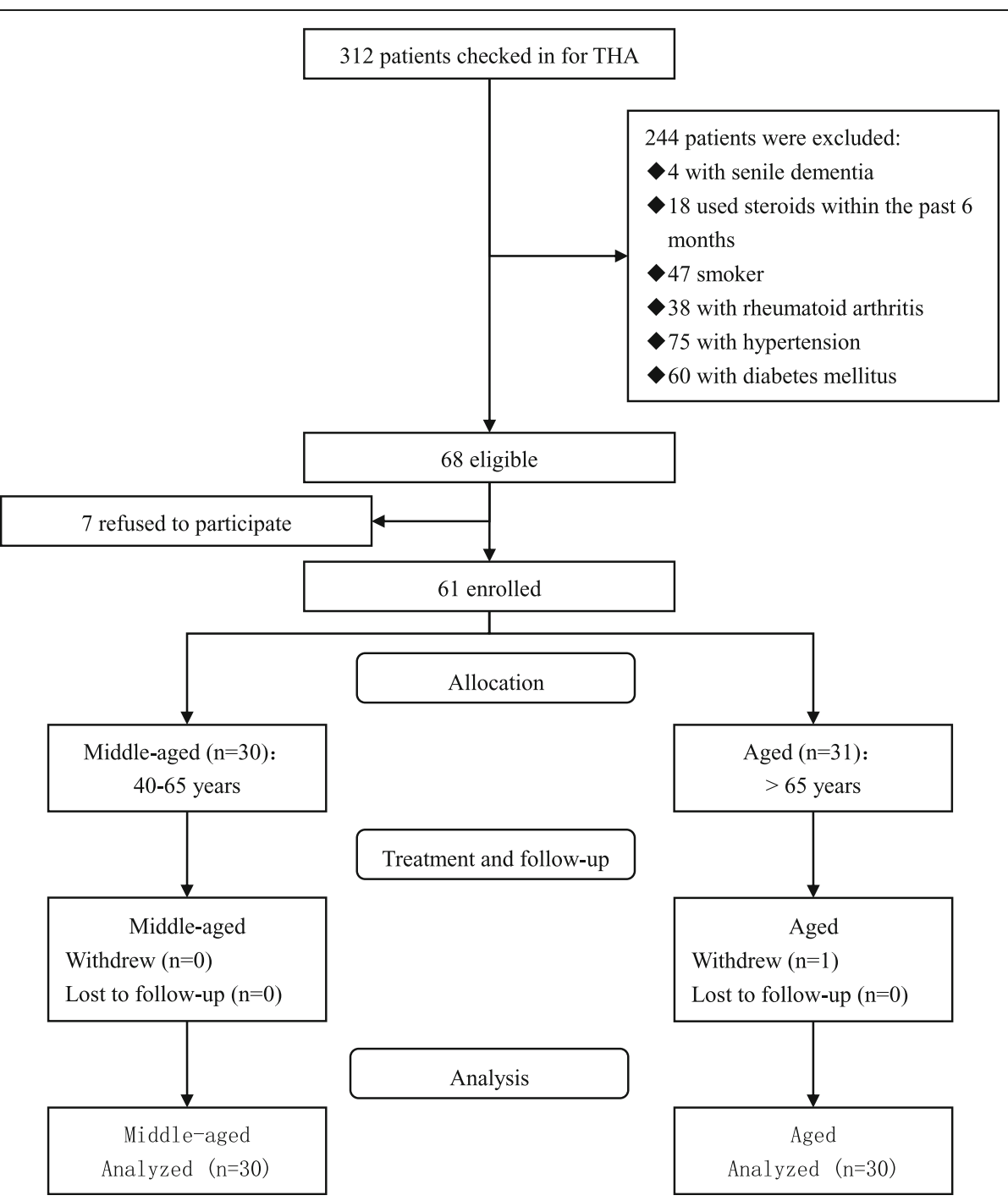

Fig. 1 The chart of patient flow in the study 
Table 1 Demographic and operative information

\begin{tabular}{lllll}
\hline Parameters & Middle-aged & Aged & $Z / X^{2} / t$ & $P$ \\
\hline Age(yrs) & $53.93 \pm 7.40$ & $71.80 \pm 5.85$ & $Z=-6.658$ & $<0.001$ \\
Gender(M/F) & $11 / 19$ & $13 / 17$ & $X^{2}=2.411$ & 0.121 \\
Height(cm) & $167.77 \pm 11.63$ & $163.30 \pm 9.10$ & $t=1.657$ & 0.103 \\
Weight(kg) & $66.33 \pm 11.88$ & $65.67 \pm 11.70$ & $t=0.219$ & 0.827 \\
BMl & $23.44 \pm 2.46$ & $24.44 \pm 2.62$ & $t=-1.525$ & 0.133 \\
Operative time(min) & $64.87 \pm 10.10$ & $63.77 \pm 11.33$ & $t=0.397$ & 0.693 \\
\hline
\end{tabular}

$156.32 \mathrm{nmol} / \mathrm{L}$ and $807.12 \pm 161.34 \mathrm{nmol} / \mathrm{L}$ in the aged and middle-aged groups, respectively. Then, the cortisol concentrations dropped to $550.99 \pm 210.73 \mathrm{nmol} / \mathrm{L}$ and $607.7 \pm 214.31 \mathrm{nmol} / \mathrm{L}$, respectively, at $24 \mathrm{~h}$ after the operation, which were still much higher than the baseline concentrations. The concentrations were almost the same at POD $3(562.63 \pm 142.7 \mathrm{nmol} / \mathrm{L}$ in the aged group and $609 \pm 153.53 \mathrm{nmol} / \mathrm{L}$ in the middle-aged group) (Table 2). The preoperative serum cortisol concentrations and the cortisol levels at 24 and $72 \mathrm{~h}$ after surgery did not significantly differ between the two groups. However, serum cortisol was significantly lower six hours after the surgical procedure in the aged group than in the middle-aged group. Serum cortisol tended to be higher in the aged group preoperatively than in the middle-aged group; an opposite trend was seen postoperatively, although the differences were not significant except at $6 \mathrm{~h}$ after surgery (Fig. 2a).

\section{Serum IL-6 levels}

The IL-6 concentration was $3.54 \pm 1.55 \mathrm{pg} / \mathrm{ml}$ for the aged group and $3.96 \pm 1.59 \mathrm{pg} / \mathrm{ml}$ for the middle-aged group before surgery, both of which were within the normal range. These concentrations increased to $64.14 \pm$ $16.43 \mathrm{pg} / \mathrm{ml}$ and $52.81 \pm 29.16 \mathrm{pg} / \mathrm{ml}$, respectively, $6 \mathrm{~h}$ after surgery and continued to rise until they peaked at $24 \mathrm{~h}$ after surgery $(165.35 \pm 50.50 \mathrm{pg} / \mathrm{ml}$ and 114.53 $\pm 56.78 \mathrm{pg} / \mathrm{ml}$ ). At POD 3, these concentrations plummeted to lower but still above-normal levels $(32.60 \pm 13.42 \mathrm{pg} / \mathrm{ml}$ and $28.99 \pm 15.01 \mathrm{pg} / \mathrm{ml}$, respectively) (Table 2). In contrast to the changes in serum cortisol, serum IL-6 was lower before surgery and higher at 6,24 , and 3 days after surgery in the aged group than in the middle-aged group, but significant differences between the two groups were observed only at 6 and $24 \mathrm{~h}$ (Fig. 2b).

\section{CRP concentration}

The CRP levels were barely changed $6 \mathrm{~h}$ after THA compared with the preoperative measurements in both groups and fell within the normal range. The CRP concentration soared to $90.47 \pm 22.44 \mathrm{mg} / \mathrm{L}$ (aged) and $81.56 \pm 21.09 \mathrm{mg} / \mathrm{L}$ (middle-aged) $24 \mathrm{~h}$ after surgery and peaked at $119.40 \pm 32.06 \mathrm{mg} / \mathrm{L}$ (aged) and $100.27 \pm$ $25.34 \mathrm{mg} / \mathrm{L}$ (middle-aged) 3 days after the operation (Table 2). The aged group maintained higher blood CRP than the middle-aged group both before and after surgery, but the increments were subtle until $24 \mathrm{~h}$ after the operation in both groups. The difference became significant 3 days after surgery, at which time the blood CRP concentration was the highest within both groups. Additionally, the CRP concentration was virtually the same 6 $\mathrm{h}$ postoperatively and preoperatively (Fig. $2 \mathrm{c}$ ).

\section{VAS evaluation}

The aged group scored $3.47 \pm 1.46$ in the preoperative VAS evaluation, whereas the middle-aged group scored $3.33 \pm 1.32$. Six hours after the operation, both groups experienced aggravated pain and scored $5.47 \pm 1.11$ and $4.87 \pm 1.07$, respectively. However, the scores in both groups decreased swiftly, with the aged group scoring

Table 2 Cortisol, IL-6 and CRP levels before and 6 h, 24 h and 3 days after THA

\begin{tabular}{|c|c|c|c|c|c|}
\hline Parameters & & Aged & Middle-aged & $t / Z$ & $P$ \\
\hline \multirow{4}{*}{$\begin{array}{l}\text { Cortisol } \\
\text { (nmol/L) }\end{array}$} & Preoperation & $314.84 \pm 89.65$ & $291.93 \pm 111.00$ & -1.38 & 0.17 \\
\hline & $6 \mathrm{~h}$ & $701.85 \pm 156.32$ & $807.12 \pm 161.34$ & 2.57 & 0.01 \\
\hline & $24 \mathrm{~h}$ & $550.99 \pm 210.73$ & $607.70 \pm 214.31$ & -0.72 & 0.47 \\
\hline & POD3 & $562.63 \pm 142.70$ & $609.00 \pm 153.53$ & 1.21 & 0.23 \\
\hline \multirow{4}{*}{$\begin{array}{l}\text { IL-6 } \\
(\mathrm{pg} / \mathrm{ml})\end{array}$} & Preoperation & $3.54 \pm 1.55$ & $3.96 \pm 1.59$ & 1.05 & 0.30 \\
\hline & $6 \mathrm{~h}$ & $64.14 \pm 16.43$ & $52.81 \pm 29.16$ & -2.48 & 0.01 \\
\hline & $24 \mathrm{~h}$ & $165.35 \pm 50.50$ & $114.53 \pm 56.78$ & -3.47 & $<0.01$ \\
\hline & POD3 & $32.60 \pm 13.42$ & $28.99 \pm 15.01$ & -1.21 & 0.23 \\
\hline \multirow{4}{*}{$\begin{array}{l}\text { CRP } \\
\text { (mg/L) }\end{array}$} & Preoperation & $3.35 \pm 1.88$ & $2.87 \pm 1.27$ & -0.61 & 0.54 \\
\hline & $6 \mathrm{~h}$ & $3.70 \pm 2.27$ & $3.14 \pm 1.88$ & -0.98 & 0.33 \\
\hline & $24 \mathrm{~h}$ & $90.47 \pm 22.44$ & $81.56 \pm 21.09$ & -1.59 & 0.12 \\
\hline & POD3 & $119.40 \pm 32.06$ & $100.27 \pm 25.34$ & -2.56 & 0.01 \\
\hline
\end{tabular}




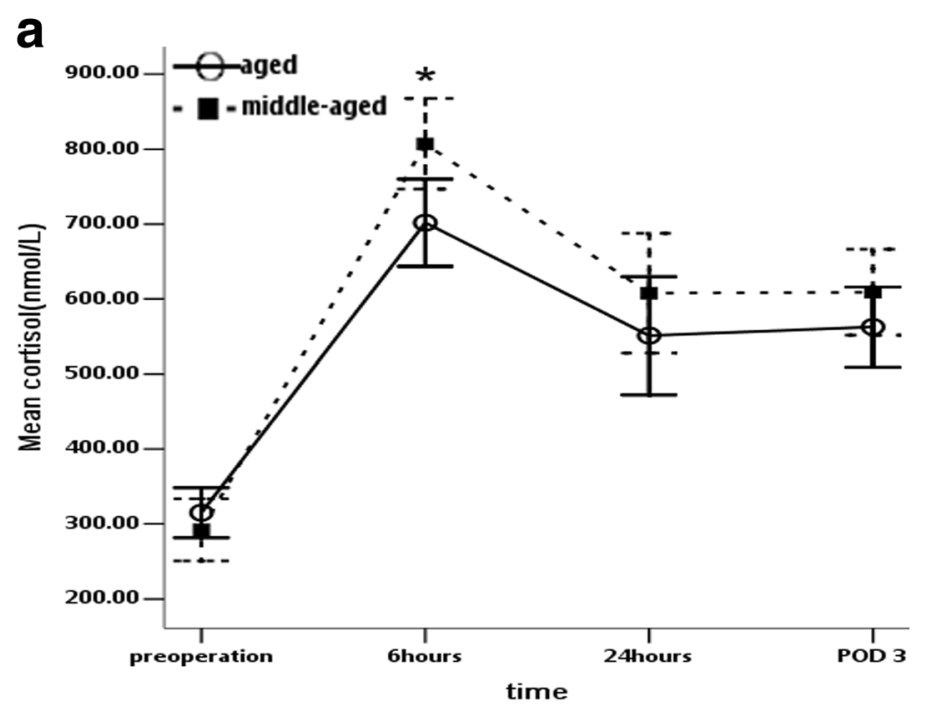

b

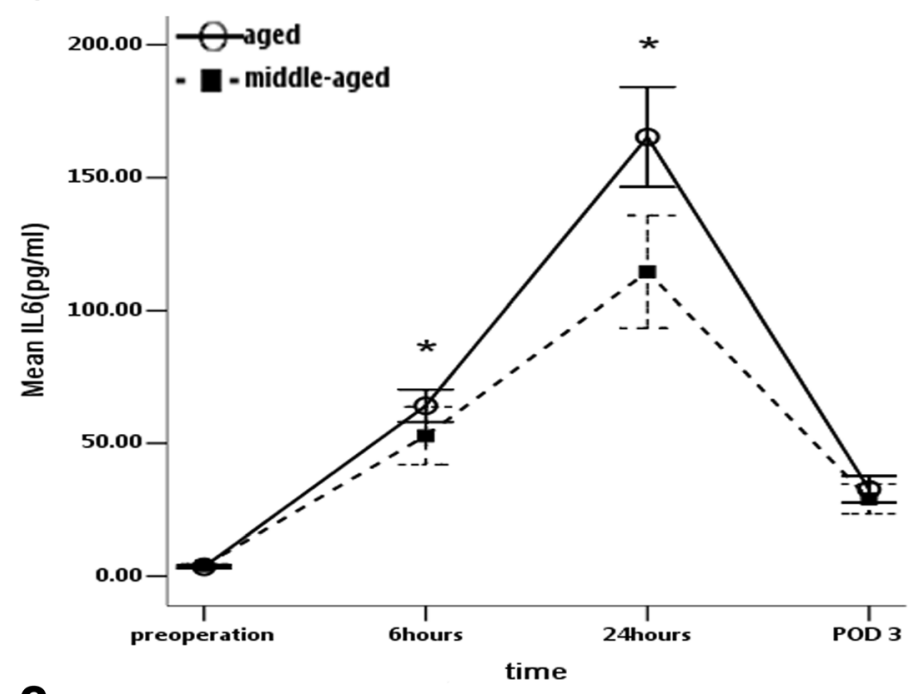

C

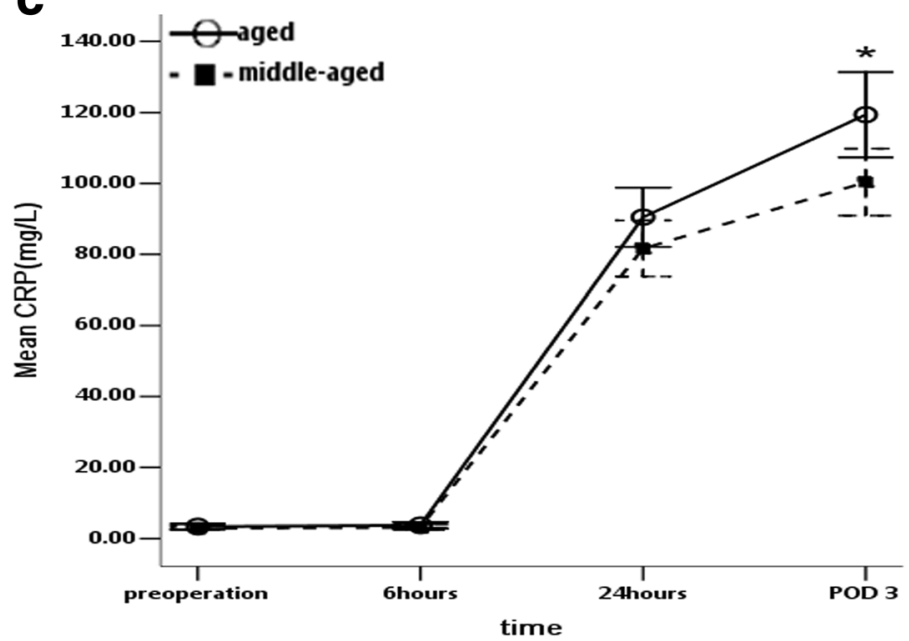

Fig. 2 The stress response (cortisol, a) and inflammatory response (IL-6 and CRP, $\mathbf{b}$ and $\mathbf{c}$ ) of middle-aged and aged patients preoperatively and at 6 h, $24 \mathrm{~h}$ and 3 days after THA. Asterisk $\left.{ }^{*}\right)$ means the difference between the two groups reached statistical significance $(P<0.05)$ 
slightly higher than their preoperative evaluation score $(3.73 \pm 0.98)$ and the middle-aged group scoring slightly lower than their preoperative rating $(3.20 \pm 1.19) 24 \mathrm{~h}$ after surgery. Then, the VAS scores in both groups fell to lower levels than their preoperative counterparts. The aged group felt more severe pain both before and after surgery than the middle-aged group, although significant differences were only shown at 6 and $24 \mathrm{~h}$ postoperatively, which was in accordance with the higher IL-6 levels in the aged group (Fig. 3a).

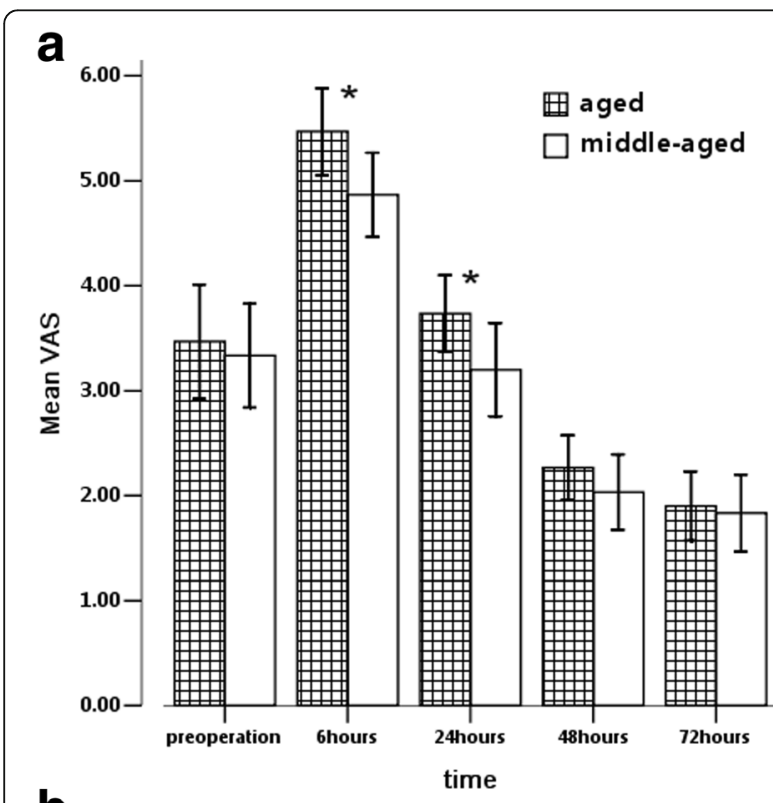

b

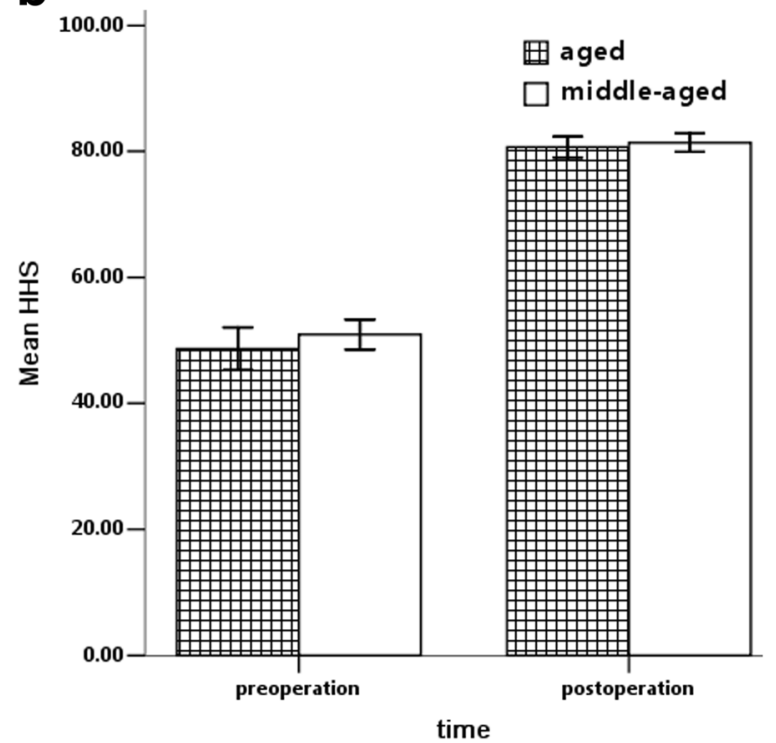

Fig. 3 a The pain assessment (VAS) of middle-aged and aged patients preoperatively and at 6, 24, 48 and $72 \mathrm{~h}$ after THA. b The function assessment (HHS) of middle-aged and aged patients preoperatively and at 3 months after THA *: $P<0.05$ comparing the two age groups

\section{HHS evaluation}

The middle-aged and aged groups scored $50.93 \pm 6.40$ and $48.67 \pm 9.11$, respectively, before THA and then $81.37 \pm 3.94$ and $80.67 \pm 4.44$, respectively, after THA. Both groups showed evident improvement in the hip function assessment after THA, but no significant differences between the two groups were shown before or after THA (Fig. 3b).

\section{Possible correlations}

The correlation analysis demonstrated only a possible weak correlation $(r=-0.37, P=0.04$, Fig. 4a) between the cortisol concentration at $6 \mathrm{~h}$ and the IL- 6 level at $24 \mathrm{~h}$ after THA in the aged group. A similar weak correlation ( $r=0.42, P=0.02$, Fig. $4 \mathrm{~b})$ was detected between the IL-6 level at $6 \mathrm{~h}$ and the VAS score at $24 \mathrm{~h}$ after THA in the aged group. These correlations were not seen in the middle-aged group. Instead, the CRP concentration at $6 \mathrm{~h}$ after THA was weakly correlated with the VAS score at $24 \mathrm{~h}$ after THA in the middle-aged group ( $r=0.39, P=0.04$, Fig. $4 \mathrm{c}$ ). The rest of the data (including the cortisol, IL-6 and CRP levels; the VAS score at time points other than the aforementioned; and the HHS in both groups) were not correlated with each other.

\section{Discussion}

To the best of our knowledge, no study in the major English language medical databases has reported differences in cortisol secretion and inflammatory responses between aged and middle-aged patients receiving THA. In this prospective observational study, we aimed to investigate the differences in the serum cortisol, IL-6 and CRP levels between aged and middle-aged patients.

This present study found that aged patients undergoing THA showed lower serum cortisol and higher IL-6 and CRP levels and more serious pain after surgery than the middle-aged patients. However, the differences between the two groups did not influence the HHS score 3 months postoperatively. The reasons for these results may be as follows. First, ageing is an inevitable physiological process that is accompanied by hypofunction of multiple body systems [13] and is related to musculoskeletal and arthritic disorders [20]. As a result, aged people often suffer suprachiasmatic nucleus impairment, which affects the hippocampus and weakens its ability to modulate the adrenocortical circadian rhythmicity [21] and stress response [22], possibly resulting in decreased circadian fluctuation of cortisol secretion [23] and a smaller increment of the serum cortisol concentration in aged people after THA. Second, IL- 6 and CRP have been broadly used as markers of the inflammatory response after operations [24]. Because CRP and IL- 6 are both related to the seriousness of tissue trauma, they are also 

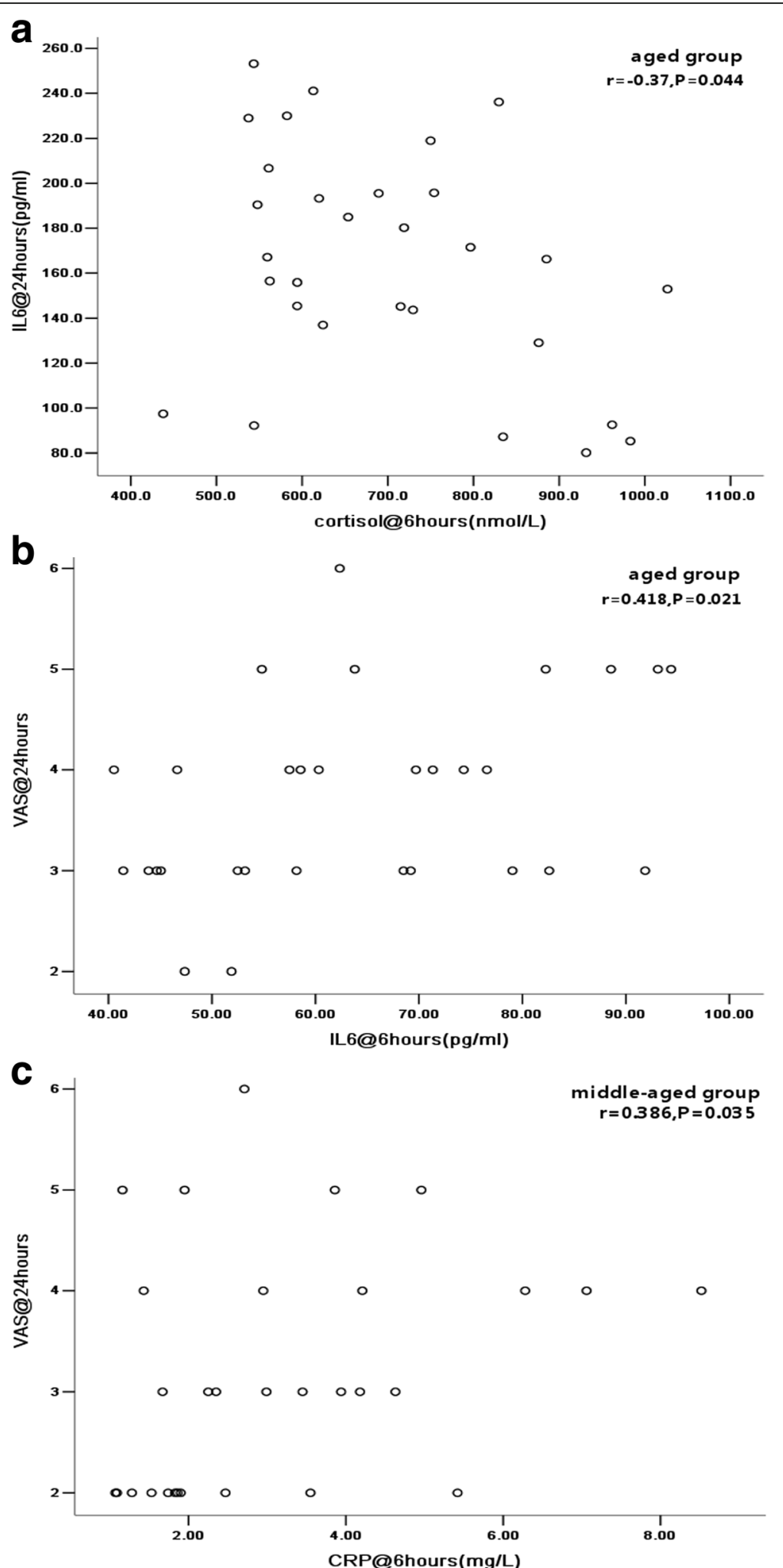

Fig. 4 a Correlation between cortisol at $6 \mathrm{~h}$ after THA and IL-6 at $24 \mathrm{~h}$ after THA in the aged group. b Correlation between IL-6 at $6 \mathrm{~h}$ after THA and VAS at $24 \mathrm{~h}$ after THA in the aged group. c Correlation between CRP at $6 \mathrm{~h}$ after THA and VAS at $24 \mathrm{~h}$ after THA in the middle-aged group 
recognized as biomarkers of the extent of surgery [25]. As a major orthopaedic surgery, THA will trigger significant increases in the serum IL-6 and CRP concentrations, which is consistent with the results of our study. The aged group exhibited a stronger inflammatory response, suggesting that aged patients experienced a greater stress response. Hall GM et al. [26] reported that a lower IL-6 concentration more rapidly and exactly predicted the ability to walk $10 \mathrm{~m}$ and $25 \mathrm{~m}$, whereas a lower CRP concentration was correlated with less pain at the time of discharge. Moreover, regardless of the nature of pain, all pain originates from inflammatory responses [27]. Thus, it is beneficial for the rehabilitation of aged patients to have a weaker inflammatory response. Third, the postoperative functional outcome of patients undergoing THA is affected by multiple factors and not only by endogenous or exogenous corticosteroids.

IL-6 and CRP are makers of inflammation, and inflammation triggers pain. Cortisol has anti-inflammatory effects; therefore, higher cortisol levels should suggest stronger anti-inflammatory efficacy and be directly correlated with lower IL-6 and CRP levels and indirectly correlated with the VAS score, at least in theory. However, in our study, only very weak correlations were found. These weak correlations could be coincidental correlations in our data. The small sample size may partially account for this unsatisfying result. There were several outliers in our data that could have weakened our results. Moreover, the use of NSAIDS for pain management could have inhibited the inflammatory response to a certain extent, thereby rendering the correlation weak or even non-significant.

Due to their potent effects on the inflammatory and immune responses, glucocorticoids have been broadly used to relieve the stress response caused by surgery [28]. In a prospective study comparing 40 patients undergoing elective total knee arthroplasty for OA, injection of a small dose of dexamethasone into the periarticular soft tissues significantly decreased the CRP concentration on the third postoperative day and IL-6 in the drainage fluid $24 \mathrm{~h}$ after the operation [29]. Peter et al. [30] found that the perioperative administration of corticosteroids significantly decreased serum IL-6 at 6 and $24 \mathrm{~h}$ after surgery. Additionally, glucocorticoids improved postoperative nausea and pain and shortened the length of hospitalization $[29,31]$. In our study, the aged patients showed lower endogenous cortisol after surgery but suffered more severe pain at $6 \mathrm{~h}$ postoperatively, implying that endogenous cortisol could not relieve the stress response and that exogenous corticosteroid should be used to improve the postoperative outcome. Unfortunately, corticosteroid is also associated with adverse events, such as hyperglycaemia, poor wound healing, deep infection and delayed bone healing [32-36]. A meta-analysis by Toner AJ et al. confirmed that perioperative administration of glucocorticoids increased the blood glucose concentration [33]. In addition, even a single surge of perioperative blood glucose is directly related to infectious and non-infectious complications [34]. In animal models, glucocorticoids significantly impaired bone healing and reduced bone turnover [35, 36]. Although whether the perioperative use of corticosteroid produces adverse effects, such as impaired wound healing and deep infection, is controversial, some studies have suggested that low-dose and short-term administrations of corticosteroid should lessen these concerns [29-31, 37-40]. Glucocorticoid can relieve the stress response and alleviate postoperative pain but does not improve the functional outcome [38]. In the present study, there was no differences in the HHS between the two groups, implying that the postoperative functional outcome of patients undergoing THA was affected by multi-factors and not only by endogenous or exogenous corticosteroid.

Several limitations should be mentioned. The number of patients recruited in our study was small, and larger samples may be needed to reveal differences between some of the variables. Celecoxib and parecoxib were administered to the patients, which suppressed the inflammatory response and affected the serum IL-6 and CRP levels. The HHS may not have been sensitive enough to reflect minute differences in the surgical outcome and patient satisfaction between the two groups. Two other limitations of our study are the short observational time and the lack of standardized follow-up methodology. To confirm and validate the results of our study, studies with a large sample size and multi-centre randomized controlled trials are needed.

\section{Conclusion}

Aged patients undergoing THA exhibited a lower level of endogenous cortisol production at $6 \mathrm{~h}$ postoperatively and a more severe inflammatory response (IL-6 at 6 and $24 \mathrm{~h}$ and CRP at 3 days after surgery) and postoperative pain (VAS at 6 and $24 \mathrm{~h}$ after surgery). Further studies of perioperative glucocorticoid usage in aged patients should be conducted to demonstrate the benefits and possible side effects.

\section{Abbreviations}

CRP: C-reactive protein; HHS: Harris hip score; IL-6: interleukin-6.; NSAIDs: Non-steroidal anti-inflammatory drugs; OA: osteoarthritis; POD: Postoperative day; THA: Total hip arthroplasty; VAS: Visual analog scale

\section{Acknowledgments}

We thank all the patients for participation in our study, and we are grateful to the staff of our department for their support and contribution in this study. 


\section{Funding}

No commercial, public, or nonprofit organizations financially supported this research.

\section{Availability of data and materials}

All data analyzed during this study are included within the manuscript and its supplementary information files. The datasets used and/or analyzed during this study are available from the corresponding author (B.S.) on reasonable request.

\section{Authors' contributions}

JZ, BS designed this study. JZ and HS were responsible for gathering, analyzing and interpreting data, and writing the manuscript. JY and ZZ made contributions to revising the manuscript for crucial intellectual content. FP, YZ, and PK have contributed in the revision of the manuscript and interpretation of data. The final version of the text has been reviewed and approved by all authors.

\section{Ethics approval and consent to participate}

This study has been approved by the Institutional Review Board at the West China Hospital, Sichuan University. Each author certifies that all investigations were conducted in accordance with ethical principles. All participants involved in the study gave their informed consent and signed and informed consent form.

\section{Consent for publication}

Not Applicable

\section{Competing interests}

The authors announce that they do not have any competing interests.

\section{Publisher's Note}

Springer Nature remains neutral with regard to jurisdictional claims in published maps and institutional affiliations.

Received: 9 May 2017 Accepted: 8 December 2017

Published online: 19 December 2017

\section{References}

1. Goldring MB, Goldring SR. Osteoarthritis. J Cell Physiol. 2007;213:626-34.

2. Sarzi-Puttini P, Cimmino MA, Scarpa R, Caporali R, Parazzini F, Zaninelli A,

Atzeni F, Canesi B. Osteoarthritis: an overview of the disease and its treatment strategies. Semin Arthritis Rheum. 2005;35:1-10.

3. Cremeans-Smith JK, Boarts JM, Greene K, Delahanty DL. Patients' reasons for electing to undergo total knee arthroplasty impact post-operative pain severity and range of motion. J Behav Med. 2009:32:223-33.

4. Fujita K, Makimoto K, Hotokebuchi T. Qualitative study of osteoarthritis patients' experience before and after total hip arthroplasty in Japan. Nurs Health Sci. 2006;8:81-7.

5. Hudak PL, Clark JP, Hawker GA, Coyte PC, Mahomed NN, Kreder HJ, Wright JG. "You're perfect for the procedure! Why don't you want it?" elderly arthritis patients' unwillingness to consider total joint arthroplasty surgery: a qualitative study. Med Decis Mak. 2002;22:272-8.

6. Toye FM, Barlow J, Wright C, Lamb SE. Personal meanings in the construction of need for total knee replacement surgery. SocSci Med. 2006;63:43-53.

7. Weissman C. The metabolic response to stress: an overview and update. Anesthesiology. 1990;73:308-27.

8. Cruickshank AM, Fraser WD, Burns HJ, Van Damme J, Shenkin A. Response of serum interleukin-6 in patients undergoing elective surgery of varying severity. ClinSci (Lond). 1990;79:161-5.

9. Wilmore DW, Long JM, Mason AD, Jr. Pruitt BA: Stress in surgical patients as a neurophysiologic reflex response. Surg Gynecol Obstet 1976, 142:257-269.

10. Chernow B, Alexander HR, Smallridge RC, Thompson WR, Cook D, Beardsley D, Fink MP, Lake CR, Fletcher JR. Hormonal responses to graded surgical stress. Arch Intern Med. 1987;147:1273-8.

11. Kellner M, Yassouridis A, Manz B, Steiger A, Holsboer F, Wiedemann K. Corticotropin-releasing hormone inhibits melatonin secretion in healthy volunteers-a potential link to low-melatonin syndrome in depression? Neuroendocrinology. 1997;65:284-90.

12. Desborough JP. The stress response to trauma and surgery. Br J Anaesth. 2000;85:109-17.
13. Lopez-Otin C, Blasco MA, Partridge L, Serrano M, Kroemer G. The hallmarks of aging. Cell. 2013;153:1194-217.

14. Ball MJ. Neuronal loss, neurofibrillary tangles and granulovacuolar degeneration in the hippocampus with ageing and dementia. A quantitative study. ActaNeuropathol. 1977;37:111-8.

15. Mani RB, Lohr JB, Jeste DV. Hippocampal pyramidal cells and aging in the human: a quantitative study of neuronal loss in sectors CA1 to CA4. Exp Neurol. 1986;94:29-40.

16. Langer P, Balazova E, Vician M, Martino E, Jezova D, Michalikova S, Moravec R. Acute development of low T3 syndrome and changes in pituitaryadrenocortical function after elective cholecystectomy in women: some differences between young and elderly patients. Scand J Clin Lab Invest. 1992;52:215-20.

17. Oyama T, Taniguchi K, Takazawa T, Matsuki A, Kudo M. Effect of anaesthesia and surgery on endocrine function in elderly patients. Canadian Anaesthetists' Society journal. 1980;27:556-9.

18. Arnetz BB. Endocrine reactions during standardized surgical stress: the effects of age and methods of anaesthesia. Age Ageing. 1985;14:96-101.

19. Blichert-Toft M, Christensen V, Engquist A, Fog-Moller F, Kehlet H, Madsen SN, Skovsted L, Thode J, Olgaard K. Influence of age on the endocrinemetabolic response to surgery. Ann Surg. 1979;190:761-70.

20. Mobasheri A, Matta C, Zakany R, Musumeci G. Chondrosenescence: definition, hallmarks and potential role in the pathogenesis of osteoarthritis. Maturitas. 2015;80:237-44.

21. Moberg GP, Scapagnini U, de Groot J, Ganong WF. Effect of sectioning the fornix on diurnal fluctuation in plasma corticosterone levels in the rats. Neuroendocrinology. 1971;7:11-5.

22. Conforti N, Feldman S. Effects of dorsal fornix section and hippocampectomy on adrenocortical responses to sensory stimulation in the rat. Neuroendocrinology. 1976;22:1-7.

23. Ferrari E, Cravello L, Muzzoni B, Casarotti D, Paltro M, Solerte SB, Fioravanti M, Cuzzoni G, Pontiggia B, Magri F. Age-related changes of the hypothalamicpituitary-adrenal axis: pathophysiological correlates. Eur J Endocrinol. 2001;144: 319-29.

24. Ohzato H, Yoshizaki K, Nishimoto N, Ogata A, Tagoh H, Monden M, Gotoh M, Kishimoto T, Mori T. Interleukin-6 as a new indicator of inflammatory status: detection of serum levels of interleukin-6 and C-reactive protein after surgery. Surgery. 1992:111:201-9.

25. Demura S, Takahashi K, Kawahara N, Watanabe Y, Tomita K. Serum interleukin-6 response after spinal surgery: estimation of surgical magnitude. J Orthop Sci. 2006;11:241-7.

26. Hall GM, Peerbhoy D, Shenkin A, Parker CJ, Salmon P. Relationship of the functional recovery after hip arthroplasty to the neuroendocrine and inflammatory responses. Br J Anaesth. 2001;87:537-42.

27. Omoigui $\mathrm{S}$. The biochemical origin of pain-proposing a new law of pain: the origin of all pain is inflammation and the inflammatory response. Part 1 of 3-a unifying law of pain. Med Hypotheses. 2007;69:70-82.

28. Holte $\mathrm{K}$, Kehlet $\mathrm{H}$. Perioperative single-dose glucocorticoid administration: pathophysiologic effects and clinical implications. J Am Coll Surg. 2002;195: 694-712.

29. Ikeuchi M, Kamimoto Y, Izumi M, Fukunaga K, Aso K, Sugimura N, Yokoyama $M$, Tani T. Effects of dexamethasone on local infiltration analgesia in total knee arthroplasty: a randomized controlled trial. Knee Surg Sports Traumatol Arthrosc. 2014;22:1638-43.

30. Sculco PK, McLawhorn AS, Desai N, EP S, Padgett DE, Jules-Elysee K. The effect of perioperative corticosteroids in Total hip arthroplasty: a prospective double-blind placebo controlled pilot study. J Arthroplast. 2016;31:1208-12.

31. Backes JR, Bentley JC, Politi JR, Chambers BT. Dexamethasone reduces length of hospitalization and improves postoperative pain and nausea after total joint arthroplasty: a prospective, randomized controlled trial. J Arthroplast. 2013;28:11-7.

32. Percival VG, Riddell J, Corcoran TB. Single dose dexamethasone for postoperative nausea and vomiting-a matched case-control study of postoperative infection risk. Anaesth Intensive Care. 2010;38:661-6.

33. Toner AJ, Ganeshanathan V, Chan MT, Ho KM, Corcoran TB. Safety of perioperative glucocorticoids in elective noncardiac surgery: a systematic review and meta-analysis. Anesthesiology. 2017;126:234-48.

34. Kiran RP, Turina M, Hammel J, Fazio V: The clinical significance of an elevated postoperative glucose value in nondiabetic patients after colorectal surgery: evidence for the need for tight glucose control? Ann Surg 2013, 258:599-604, 604-605. 
35. Bissinger O, Kreutzer K, Gotz C, Hapfelmeier A, Pautke C, Vogt S, Wexel G, Wolff KD, Tischer T, Prodinger PM. A biomechanical, micro-computertomographic and histological analysis of the influence of diclofenac and prednisolone on fracture healing in vivo. BMC Musculoskelet Disord. 2016;17:383.

36. JH F, Bashutski JD, Al-Hezaimi K, Wang HL. Statins, glucocorticoids, and nonsteroidal anti-inflammatory drugs: their influence on implant healing. Implant Dent. 2012;21:362-7.

37. Salerno A, Hermann R. Efficacy and safety of steroid use for postoperative pain relief. Update and review of the medical literature. J Bone Joint Surg Am. 2006;88:1361-72.

38. Bergeron SG, Kardash KJ, Huk OL, Zukor DJ, Antoniou J. Perioperative dexamethasone does not affect functional outcome in total hip arthroplasty. ClinOrthopRelat Res. 2009:467:1463-7.

39. Sauerland S, Nagelschmidt M, Mallmann P, Neugebauer EA. Risks and benefits of preoperative high dose methylprednisolone in surgical patients: a systematic review. Drug Saf. 2000;23:449-61.

40. Iwamoto J, Seki A, Sato Y, Matsumoto H, Tadeda T, Yeh JK. Vitamin K2 promotes bone healing in a rat femoral osteotomy model with or without glucocorticoid treatment. Calcif Tissue Int. 2010;86:234-41.

\section{Submit your next manuscript to BioMed Central} and we will help you at every step:

- We accept pre-submission inquiries

- Our selector tool helps you to find the most relevant journal

- We provide round the clock customer support

- Convenient online submission

- Thorough peer review

- Inclusion in PubMed and all major indexing services

- Maximum visibility for your research

Submit your manuscript at www.biomedcentral.com/submit 